\title{
КИТАЙ В РУССКОЙ КЛАССИЧЕСКОЙ ЛИТЕРАТУРЕ
}

\section{Красноярова Анна Александровна}

к.фил.н., преподаватель Шандунский педагогический университет Цзинань, Китай

\begin{abstract}
Аннотация: В работе рассматривается феномен изображения Китая в русской литературы, который назван «китайским текстом» и раскрываются особенности его функционирования в русской культуре XIX-XX вв. «Китайский текст» интерпретируется как единый «сверхтекст», объединяющий изображение Китая, его истории и природы, воспроизведение его культурных реалий (нравственно-философских идей, мифологем, мотивов и образов) и позволяющий на китайском материале поставить важные для культуры обеих стран проблемы: соотношение «традиций» и «прогресса», пути духовного развития человека и человечества и многие другие.

Ключевые слова: «Китайский текст», образ Китая, русская литература, синология.
\end{abstract}

\section{CHINA IN RUSSIAN CLASSICAL LITERATURE}

\section{Krasnoyarova Anna Aleksandrovna}

\begin{abstract}
Russian literature considers the phenomenon of the image of China in Russian literature, which is called the "Chinese text" and reveals the features of its functioning in Russian culture of the XIX-XXI centuries. The "Chinese text" is interpreted as a single "supertext" that combines the image of China, its history and nature, the reproduction of its cultural realities (moral and philosophical ideas, mythologies, motifs and images) and allows the Chinese material to pose important problems for the culture of both countries: the ratio of "traditions" and "progress", the ways of spiritual development of man and humanity, and many others.
\end{abstract}

Key words: "Chinese text", the image of China, Russian literature, sinology. 
В российском литературоведении 1990-2000-х годов стало популярным исследование различных вариантов «тематических текстов» «венецианского» [1], «петербургского» [2], «пушкинского [3], «пермского» [4] и др. Под «тематическим текстом» в данном случае понимается объединение произведений искусства (в частности, литературы) вокруг определённого материала - «топоса» («художественного пространства» стран или городов: Италии, Венеции, Москвы, Петербурга и т.п.) - или личности выдающегося деятеля культуры (А.С. Пушкин, С.П. Дягилев).

Понятие «текст» в данном случае используется в значении, которое употреблялось Ю.М. Лотманом [5] и постструктуралистами [6]: как сложное структурированное целое, «текст культуры», связанный с множеством текстов и контекстов, многообразно пересекающихся друг с другом [7]. В филологии такие тексты называют сверхтекстами, выражающими «совокупность высказываний», ограниченных «темпорально и локально», объединенных «содержательно и ситуативно», характеризующихся «цельной модальной установкой» и «достаточно определенными позициями адресанта и адресата» $[8$, c. 215].

Любой «сверхтекст» является системой, объединенной ценностносмысловой общностью, наличием связанных с ним «образов культуры» и многочисленных внетекстовых реалий. Эти особенности сверхтекста В.Н. Топоров охарактеризовал так: «...Все "множественно-различное", “пестрое" индивидуально-оценочное вовлекается в это поле, захватывается им и как бы пресуществляется в нем в плоть и дух единого текста. < ..> Именно в силу этого “субъективность” целого поразительным образом обеспечивает <... “объективность” частного» [2, с. 261]. На другие качества «сверхтекста» указал В.В. Абашев: «В стихийном и непрерывном процессе символической репрезентации места формируется <..> стабильная сетка семантических констант. Они становятся доминирующими категориями $<\ldots>$ и начинают $<\ldots>$ программировать этот процесс в качестве <..> матрицы новых репрезентаций...» $[4$, с. 11-12].

Среди разнообразных «сверхтекстов», созданных русской культурой, особое место занимают произведения, в которых Китай описывается как особое художественное пространство («художественный мир»), как собирательный образ, связанный с судьбами персонажей и обусловливающий развитие сюжета. «Сверхтекст», созданный такими произведениями, в дальнейшем будет называться «китайским текстом». 
Китайский текст объединяется не только изображением Китая, его истории и природы, но воспроизведением культурных реалий, обращением к многочисленным текстам культуры, национальным религиозно-философским идеям, мифологемам, образам и сюжетам, отдельным стилевым и сюжетнокомпозиционным приёмам, используемым китайской словесностью. Китайский текст включает многочисленные описания Китая и образы китайцев в художественной литературе и публицистике, мемуарные произведения («литературу путешествий», воспоминания русских эмигрантов), а также произведения, в которых использованы отдельные сюжеты и мотивы, связанные с китайской культурой. Изучение китайского текста российским литературоведением практически не проводилось. Немногочисленные работы посвящены либо отдельным аспектам (например, политологическому [9], либо творчеству известных писателей, в произведениях которых упоминался Китай.

Формирование в русской литературе китайского текста началось в XVIII в., когда Россия включилась в общеевропейскую традицию обращения к «китайскому стилю» шинуазри, который влиял на архитектуру, оформление интерьеров, живопись, женскую моду, предполагавшему использование символики и деталей, связанных с китайским искусством. Однако в рамках стиля обращение к китайской культуре оставалось поверхностным, касающимся отдельных приёмов; при этом сущность традиций и стоящая за ней философско-этическая система, жизнь народа оставались вне понимания и не сопровождались углублённой «просветительской» и «интеллектуальной» любовью к Китаю.

Интерес к Китаю в России усилился в последнюю треть XVIII в. (период правления императрицы Екатерины II), когда российский читатель получил возможность читать китайскую литературу в переводах с языков-посредников (французского, английского, маньчжурского). Так, например, именно с французского языка писатель и дипломат Д.И. Фонвизин в 1779 г. осуществил перевод важнейшего для китайской культуры текста «Да сюэ» («Великое учение»). В дальнейшем стали печататься переводы, выполненные непосредственно с китайского языка. Учёный и дипломат А.Л. Леонтьев в 1780-е гг. перевёл канонические книги - «Ицзин», «Да сюэ», «Чжун юн» [10]. Большую роль в формировании представлений о Китае и развитии школы перевода сыграла деятельность Российской Духовной миссии в Пекине (существовавшей с 1715 г.), в которой, помимо А.Л. Леонтьева, трудились 
многие известные исследователи - П.И. Каменский (1765-1845), о. Иакинф [Н.Я. Бичурин] (1777-1853), С.В. Липовцев (1770-1841), архимандрит Палладий [П.И. Кафаров] (1817-1878), В.П. Васильев (1818-1900) и др.

Публикации о Китае и переводы китайских классических текстов сформировали в сознании русской публики интерес к стране и способствовали возникновению первичного «фона» - «китайского контекста». Существенное продвижение в этом направлении произошло в XIX в. Основным объектом переводов с китайского языка стали исторические сочинения, которые, с одной стороны, давали русским читателям представление об истории соседней страны, а, с другой, - вызывали в их сознании параллели с отечественным прошлым.

Интерес русской литературы к Китаю был частью общего внимания к Востоку. Периодические журналы (например, «Вестник Европы») систематически размешали на своих страницах описания путешествий по странам Востока, переводы восточной поэзии и прозы. Особой популярностью у русских читателей пользовались путевые заметки о странах Востока, содержавшие яркие оригинальные образы и сюжеты.

Вычленение из «темы Востока» особой «китайской темы» произошло в 1830-е годы (одной причиной этого стало появление большого количества информации о Китае). Например, в романе-утопии В.Ф. Одоевского «4338-й год: Петербургские письма» (1835 г.) Россия и Китай интерпретировались как два главных мировых центра. В дальнейшем именно сопоставление этих стран легло в основу «китайского текста».

Реже появлялись произведения, в которых описывались повседневные обычаи и нравы китайцев. В 1832 г. в альманахе «Северные цветы», издававшемся А.С. Пушкиным, был опубликовал анонимный перевод фрагмента из китайского романа XVII в. «Хао цю чжуань» («Счастливый брак»), в котором повествовалось о судьбе двух молодых людей: учёного юноши Те Чжунюе и дочери сановника Шуй Бинсинь. В 1835 г. 3.Ф. Леонтьевский создал повесть «Путешественник», использовав сюжет классической китайской драмы писателя Ван Шифу «Си сян цзи» («Западный флигель»). Фрагмент этого текста был опубликован в 1936 г. в «Библиотеке для чтения», издававшейся О.И. Сенковским [11].

На протяжении XIX вв. русская литература постепенно формировала у читателей представления об истории, природе, быте, традициях, религии и философии Китая. Первоначально (под влиянием популярной в России 
французской культуры) образ Китая был в значительной мере идеализированным и экзотичным; в дальнейшем он постепенно изменялся и ставился частью развёрнутой, конкретной и исторически правдивой системы представлений о китайском быте и культуре. Итоговым произведением русской литературы первой половины XIX в., в котором представлен реалистический образ Китая, стал «географический роман» И.А. Гончарова «Фрегат Паллада», написанный в 1855-1855 гг. и опубликованный в 1858 г., в котором автор с симпатией описал китайский национальный характер, особо отмечая среди качеств, присущих представителям народа, трудолюбие, смиренность, усердие, отсутствие фанатизма, доброжелательность, учтивость и честность, тесно связанные с представлениями о сыновней почтительности и «долге».

В романе «Фрегат “Паллада”» выявилась важнейшая особенность «китайского текста» литературы: для русских писателей и читателей «Китай» оказывался интересен не сам по себе, не как экзотическое, не знакомое русскому читателю место действия, а как особый многообразный мир, который, с одной стороны, постоянно противопоставляется России, а с другой - во многом похож на нее. Китайский текст позволял поставить ещё одну важную - как для русской, так и китайской культуры - проблему, связанную с определением меры статики («застоя») и динамики («прогресса») в историческом развитии.

На протяжении XIX в. китайский текст стал занимать в русской культуре достаточно большое место (и в этом плане он оказался вполне сопоставимым с «итальянским», «московским», «петербургским» или «пушкинским» текстами), что может быть объяснено огромной значимостью жизни страны - близкого соседа России - для понимания собственной истории и культуры. Россия и Китай - два государства, исторический путь и культурные парадигмы которых, с одной стороны, принципиально различались, а, с другой стороны, - при всем своеобразии - имели черты, сопоставление которых помогало понять существенные особенности исторического пути России и национальный характер.

Китайский текст помогал российским писателям и читателям лучше представлять перспективы России и закономерности её развития, способствовал осмыслению места личности и «голоса» героя в общественной жизни того или иного периода. Большую роль в создании «китайского текста» сыграли - кто в большей, кто в меньшей степени - такие писатели, как 
А.С. Пушкин, И.А. Гончаров, Л.Н. Толстой, Ф.М. Достоевский, А.П. Чехов, И.А. Бунин, Н.С. Гумилёв и многие другие.

Китайский текст русской литературы оказался организован иначе, чем, например, развитый в русской литературе «итальянский» текст. Италия была страной, которую в хорошо знали и часто посещали не только российские писатели, художники, музыканты, но и значительная часть дворянства и определенная часть разночинной интеллигенции. Итальянское искусство, жизнь итальянского народа были достаточно хорошо известны и близки российскому читателю, а итальянская культура, сохраняя, естественно, статус «чужой», в итоге оказывалась все-таки «своей-чужой» культурой. Китай, который - в отличие от Италии - был «не освоенным» в культурном плане государством и поэтому долгое время оставался для российского читателя страной экзотической, «загадочной», в связи с чем для китайского текста русской литературы особенно важными оказывались проблемы восприятия и интерпретации. Значительную часть информации о стране российские читатели получали из переводов произведений китайской словесности.

Качественно новый этап формирования и развития «китайского текста» связан с работами русских китаеведов (А.А. Татаринова, М.Д. Храповицкого, академика В.П. Васильева и др.), которые в 1850-1880-е годы опубликовали множество научных трудов по истории и культуре Китая, Манчжурии, Тибета, Монголии, а также переводы китайских классических философских текстов (в том числе книги Лаоцзы, Конфуция, Менцзы и др. мыслителей) и произведений китайской литературы и фольклора. Их исследования и переводы, в которых воспроизводились история и современное состояние Китая (его природа и культура, быт и обычаи местного населения и окружающих народов) были известны не только специалистам-востоковедам, но и широкому кругу российских читателей, поскольку обладали яркой художественно-публицистической формой и печатались в популярной периодике (газетах «Северная пчела», «Новое время», «Биржевые ведомости», «Голос»; журналах «Современник», «Издание Русского Географического Общества» и др. издания) [12].

Огромную роль в развитии китайского текста русской литературы сыграл Л.Н. Толстой. Китай привлёк писателя в 1860-е годы, когда страна подверглась интервенции со стороны ряда европейских государств оправдываемой необходимостью насильно «внушать китайцам идею прогресса», что вызвало возмущение русского писателя [13, с. 135-136, 139]. 
Особый интерес к изучению китайских философских учений - даосизму и конфуцианству - возник у Л. Толстого как следствие духовного кризиса 1870-1880-х гг. Результатом стало появление трактата «Китайская мудрость. Книги Конфуцы» (1884 г.), в которых писатель раскрыл собственное понимание китайской философско-этической системы: утверждение ценности образования и необходимости следовать высоким нравственным принципам («человеколюбию», «гуманности», «всеобщей любви», сочувствие народу, внимание к духовной стороне жизни). Л. Толстой неоднократно обращался к идеям китайской культуры (статья «Так что же нам делать?», очерк «Сиддарта, прозванный Буддой», дневники 1881-1887 гг., книга «Путь жизни»); он стал первым русским писателем, который активно общался мыслителями Востока, в частности, с китайскими публицистами Чжан Цинтуном и Гу Хунмином [14]. Л. Толстой был убежден в духовной близости России и Китая. «Вполне согласен с вами, - писал он в 1905 г., обращаясь к Чжан Чинтуну, - что есть внутренняя, духовная связь между двумя великими народами, русским и китайским, и им надо идти рука об руку» $[15$, с. 63]. В письме Ку Хунмину («Письмо к китайцу», 1906 г.) Л. Толстой подчеркнул, что общая миссия России и Китая «...состоит в том, чтобы указать народам тот истинный путь к свободе, для выражения которой на китайском языке нет другого слова, кроме Тао, пути, т.е. деятельности, сообразной с вечным основным законом жизни человеческой» [16, с. 291-292, 295].

Отметим, что образ Поднебесной формировался не только в культурном сознании российской интеллигенции - писателей, учёных, дипломатов. В начале XX в. более-менее определённые представления о Китае стали возникать и у «непривилегированных» слоёв населения (в том числе у крестьян, ремесленников, мелких торговцев), так или иначе связанных с Китаем, которые получили возможность узнавать о дальневосточном регионе через газеты, проповеди священников, небольшие брошюры (в виде которых издавались некоторые труды русских и европейских путешественников, отдельных знатоков и исследователей Китая).

Эти брошюры - в связи с возраставшим интересом городского населения к особенностям китайской государственной жизни, быту и нравах жителей страны - печатались массовыми тиражами. Язык книжек был простым и понятным, близким к разговорному; текст, как правило, сопровождался множеством картинок «уличной жизни» китайских городов. Таковы были книги «Наши азиатские соседи китайцы» В. Маракуева [17], 
«Как живут и работают китайцы» И. Селивановского [18], «Китай и китайцы» Н. Фольбаума [19] и некоторые другие аналогичные издания.

Представления о Китае в это время чаще всего составлялись на основе личного опыта. Во время постройки КВЖД большое количество рабочих, мелких служащих и инженеров, работавших на территории Китая, могли познакомиться с Маньчжурией и её обитателями. В российской «полосе отчуждения» КВЖД предполагалось разместить небольшие совместные предприятия и фактории, наладить промыслы и разработку полезных ископаемых, а это привлекало в Маньчжурию российских промышленников и купеческое сословие. После занятия Дальнего (Далиенваня, Даляна) и Порт-Артура большое количество офицеров и простых солдат регулярных войск также имели возможность познакомиться с жителями Китая.

Русские солдаты, побывавшие в Китае, в своих письмах к родным описывали не только о военные будни, но и всё то, что они увидели в необычной для них стране. Рассказы и воспоминания солдат, вернувшихся в родные деревни с восточного фронта, воспринимались их крестьянами с огромным интересом [20, с. 436-436].

Тем не менее, в сознании значительного количества представителей российского общества Китай был богатой и преуспевающей страной, в которой, несмотря на особую любовь «бусурманских» китайцев к азартным играм и опиокурению, а также естественное для любого человека стремление к наживе, проживает миролюбивый, выносливый и вежливый народ.

Над всеми этими представлениями, существовавшими в русской культуре начала XX в., в литературе последующих периодов «надстраивался» образ Китая.

Анализ русской культуры и литературы последней трети XVIII - начала $\mathrm{XX}$ в. показывает, что в течение этого периода в ней сформировалась традиция обращения к мотивам, образам и сюжетам, соотносившимся с китайской культурой, что позволяет сделать вывод о появлении в ней «китайского текста». В свою очередь, возникновение в рамках художественной литературы конца XIX - начала XX в. «китайского текста» способствовало дальнейшему развитию в общественном сознании представлений о Китае (или «образа Китая»).

Исследование процесса формирования в России представлений о Китае и китайской культуре позволяет сделать основной вывод: в период, предшествующий Первой Мировой войне и Гражданской войне, в русской 
культуре сформировались развёрнутый «китайский контекст» и многообразный «китайский текст», который, с одной стороны, стал важным источником информации о соседней стране, с другой - использовался в качестве материала для размышлений о самой России и о проблемах её исторического развития.

Мысль об исторической и духовной близости России и Китая, а также о сходстве проблем, стоящих перед обеими странами, сформулированная в литературе XIX в., стала одной из основополагающих для «китайского текста» русской литературы XX в., когда, с одной стороны, Россия и Китай действительно оказались в сходных политических ситуациях, a, с другой, большое количество российских людей оказалось на территории Китая, что привело как к росту «количества» произведений, изображающих Китай, так и структурному усложнению «китайского текста».

Мысль об исторической и духовной близости России и Китая, а также о сходстве проблем, стоящих перед обеими странами, сформулированная в литературе XIX в., стала одной из основополагающих для «китайского текста» русской литературы XX в., когда, с одной стороны, Россия и Китай действительно оказались в сходных политических ситуациях, a, с другой, большое количество российских людей оказалось на территории Китая, что привело как к росту «количества» произведений, изображающих Китай, так и структурному усложнению «китайского текста».

\section{Список литературы}

1. Меднис Н.Е. Венеция в русской литературе. - Новосибирск, 1999. $391 \mathrm{c}$.

2. Топоров В.Н. Миф. Ритуал. Символ. Образ: исследования в области мифопоэтического: избранное. - М.: Прогресс; Культура, 1995. - 621 с.

3. Гаспаров Б.М. Язык, память, образ. Лингвистика языкового существования. - М.: Новое лит. обозрение, 1996. - 351 с.

4. Абашев В.В. Пермь как текст. Пермь в русской культуре и литературе XX века. - Пермь: Изд-во Пермского ун-та, 2000. - 492 с.

5. Лотман Ю.М. Внутри мыслящих миров. - СПб.: Азбука, 2016. $444 \mathrm{c}$.

6. Барт Р. Избранные работы: Семиотика. Поэтика: пер. с фр. / Р. Барт, сост., общ. ред. и вступит. ст. Г.К. Косикова. - М.: Прогресс, 1989. - 615 с. 
7. Ильин И.П. Поструктурализм // Современное зарубежное литературоведение: концепции, школы, термины. Энциклопедический справочник. - М.: Интрада-ИНИОН, 1999. - С. 97-105.

8. Купина Н.А., Битенская Г.В. Сверхтекст и его разновидности // Человек - текст - культура: коллектив. моногр. / под ред. Н.А. Купиной, Т.В. Матвеевой. - Екатеринбург, 2004. - С. 214-233.

9. Лукин А.В. Медведь наблюдает за драконом. Образ Китая в России в XVII - XXI вв. - М.: Восток-Запад; АСТ, 2007. - 598 с.

10. Кобзев А.И. Судьба «Да-сюэ» в России и на Западе (исследование и перевод) // Архив российской китаистики. Т 2. - М.: Наука [Восточная литература], 2013. - С. 150-211.

11. Иванова М.В. Из истории востоковедения в России (XVIII в. - 1917 г.): учебное пособие / М.В. Иванова; Томский политехнический университет. - Томск: Изд-во Томского политехнического университета, 2010. - 105 с.

12. Восток в русской литературе XVIII - начала XX века. Знакомство. Переводы. Восприятие. - М: ИМЛИ РАН, 2004. - 256 с.

13. Толстой Л.Н. Статьи. - М.: Директ-Медиа, 2010. - 340 с.

14. Шифман А.И. Лев Толстой и Восток. 2-е изд., перераб. и дополн. М., 1971. - $552 \mathrm{c}$.

15. Толстой Л.Н. Полное собрание сочинений: в 90 т. - М.: Государственное изд-во художественной литературы, 1928-1958. Т. 76. Письма 1905 (июль - декабрь). - М.: Гос. изд-во худож. лит-ры, 1956.

16. Толстой Л. Н. Полное собрание сочинений в 91 томе. М.: Терра, 1992

17. Маракуев В.Н. Наши азиатские соседи китайцы (составлено по Р. Дугласу, Симону, Э. Реклю, Леггу и др.) / В.Н. Маракуев. Одесса, 1896. $190 \mathrm{c}$.

18. Селивановский И.П. Как живут и работают китайцы / А.П. Селивановский. М., 1904. 80 с.

19. Фольбаум Н. Китай и китайцы / Н. Фольбаум. М., 1911. 52 с.

20. Громыко М.М. О воззрениях русского народа / М.М. Громыко, А.В. Буганов. М.: Пальмникъ, 2000. 541 с. 